\title{
Detecting Buried Human Bodies Using Ground-Penetrating Radar
}

\author{
Widodo ${ }^{1}$, Iqbal F. Aditama ${ }^{1}$, Khalid Syaifullah ${ }^{1}$, Muthi'a J. Mahya ${ }^{1} \&$ M. Hidayat ${ }^{1}$ \\ ${ }^{1}$ Geophysical Engineering, Bandung Institute of Technology, Bandung, Indonesia \\ Correspondence: Widodo, Geophysical Engineering, Bandung Institute of Technology, Bandung, 40132, \\ Indonesia. Tel: 6222-253-4137. E-mail: widodo@gf.itb.ac.id
}

Received: January 24, 2016

Accepted: March 9, 2016

Online Published: April 8, 2016

doi:10.5539/esr.v5n2p59

URL: http://dx.doi.org/10.5539/esr.v5n2p59

\begin{abstract}
Being located at the dense tectonic activity area, Indonesia has to cope with the constant risk of earthquakes. High frequency of earthquakes occurrence causes the crust instability and leads into another natural disaster such as landslides. Sometimes, the landslide avalanches are covering the high populated area destroying buildings and causing victims. Unfortunately, the treatment for the affected building and landslide victims searching are still using conventional methods. The purpose of this study is to detect buried human bodies using GPR method, so it can increase the effectiveness and the efficiency of disaster victims searching under the landslide avalanche. Ground-penetrating radar (GPR) is one of the geophysical methods that can be used to study shallow subsurface of the earth. GPR has been successfully used to locate grave and forensic evidence. However, more controlled research is needed to improve the effectiveness and efficiency of disaster victim detection that buried under landslides or earthquake avalanche. A detailed GPR survey was conducted in the Cikutra graveyard, Bandung, with corpses buried one week until two months before the survey. The radar profiles from this survey showed the clear amplitude contrast anomalies, emanated from the corpses. The strongest amplitude contrasts are observed at most recent grave compared to the older grave. We obtained the amplitude contrast at around 1.2 meters depth which is consistent with the depth of the buried corpses. In addition, the results of forward modeling of homogenous subsurface and corpses in subsurface will be presented.
\end{abstract}

Keywords: buried corpse, earthquakes, GPR, human bodies, landslides

\section{Introduction}

Indonesia is located at the ring of fire and is the one of the densest center of seismic activity in the world. Earthquakes and landslides occur frequently and cause a lot of victims. In Indonesia, the searching of victims buried under landslide or earthquake avalanches is still using conventional methods by sniffer dog or random searching at the human activity area. The conventional method was taking too much time and sometime left some victims unfound. The use of conventional method was due to the absence of technology application that able to search the buried victim effectively and efficiently. The purpose of this study is to prove that the GPR method can be used to detect human bodies underground, so it would be applicable for disaster victims searching in more effective and efficient way. Buried victims under landslide or earthquake avalanche are approximated by buried corpses in the graveyard. The study site is located within the Cikutra burial ground, in the northern area of Bandung city of longitude $107^{\circ} 38^{\prime} 13.4^{\prime \prime E}$ and latitude $6^{\circ} 53^{\prime} 23.5^{\prime \prime}$ S. The survey was taken at October 16,2015 , at eleven adjacent graves. The corpses buried one week until two months before the survey was available. The choosing of the new buried bodies was to approximate the real disaster case where the searching of victim bodies is done as soon as the disaster happened. The process of the burial includes wrapping of the corpse body with a sheet of shroud and then placing the body in the grave. The topography of the study site was relatively flat with increasing elevation $10 \mathrm{~cm}$ right above each grave. The Cikutra graveyard consists of very dry soil (Figure 1) that mostly contain small air cavities or cracks resulted from overexposure of the sun and the minimal amount of vegetation. 


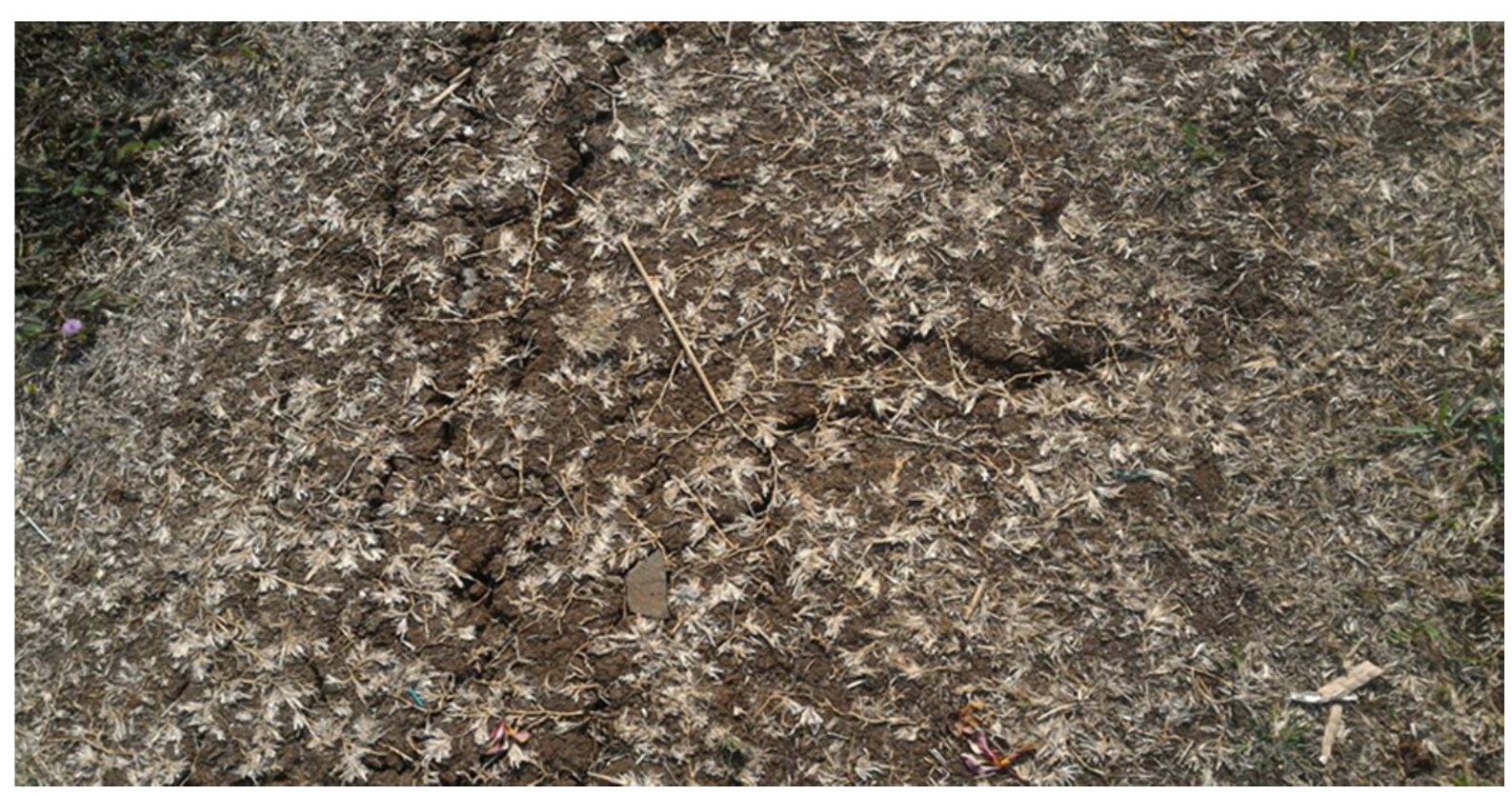

Figure 1. Soil condition at the survey area

GPR is a geophysical method that transmits electromagnetic (EM) waves from the antennas into the ground. GPR can accurately map the shallow subsurface by detecting the changes of electrical properties. Bed boundaries and other discontinuities in the ground will reflect the wavelet back to the surface and got recorded (Conyers, 2013). GPR measures the time between EM wave transmission and reception, referred as the two-way travel time that commonly measured in nanoseconds, which is a function of reflector depth and the EM wave propagation velocity (Robinson et al., 2004). As the radar waves are transmitted through various materials on their way to the buried target, their velocity will change depending on the physical properties of the material through which they traveled (Neal, 2004). If the travel times of the EM wave are measured, and the velocity through the ground is known, the distance from antenna as the source of GPR wave and the reflection point can be accurately measured (Conyers and Goodman, 1997). For GPR to works effectively, the target must exhibit electrical properties (dielectric constant and electrical conductivity) which contrast with the host subsurface (Neal, 2004). Subsurface discontinuities where reflections occur are usually created by changes in the electrical or magnetic properties of the rock, sediment or soil (Conyers and Goodman, 1997). By the electrical properties contrast of dry soil, human blood, and human bones, it is predicted that the GPR survey at graveyard will show a clear anomaly indicating the buried human body location.

The success of GPR research to detect the human bone is present by Mellett (1992) that was able to locate a buried victim of a homicide $0.5 \mathrm{~m}$ deep using a $500 \mathrm{MHz}$ antenna. Hammon et al. (2000) forward modeled GPR responses from human remains using different frequencies and found that a skull was detectable at $0.8 \mathrm{~m}$ depth in the dry sand. Damiata et al. (2013) can detect the human bone inside a well buried grave. The principle of the search is based on the contrast of the electric permittivity and the magnetic permeability of the bone with its surroundings. The circle in Figure 2 shows a radargram that isolate the hyperbolas associated with the excavated grave. Arrows point to reflections from various types of reflectors such as a stratigraphic layering, an enclosure wall and a chest cavity. 


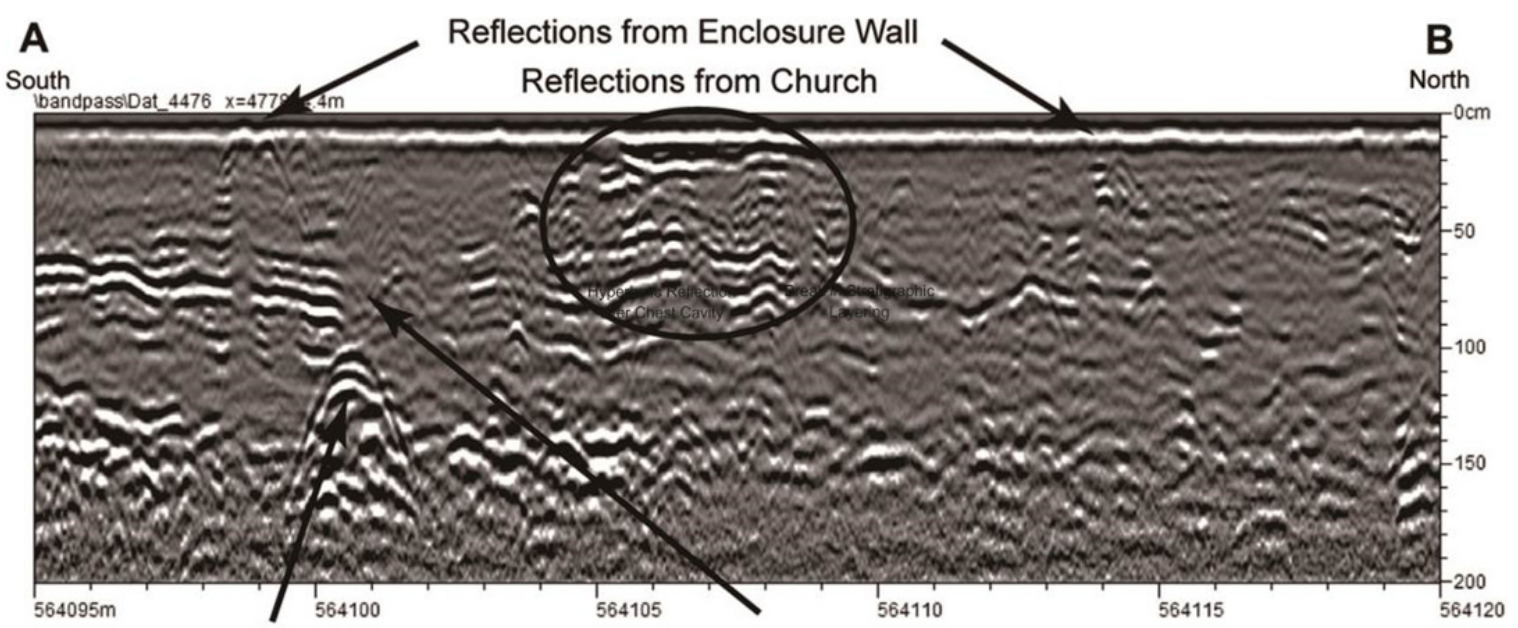

Figure 2. The GPR response to a human bone shows a hyperbolic reflection (modified from Damiata (2013))

\section{Method}

The GPR equipment used for this survey was MALA RAMAC X3M $800 \mathrm{MHz}$ shielded antenna powered by a separate battery. The use of $800 \mathrm{MHz}$ antenna reasoned for it can cover the observation depth of the survey that well resolved until 6 meters depth. Data was recorded and managed through a laptop connected to the equipment with RamacGroundVision software. The output appearance is indicating the continuity of data sampling used as survey quality control. We also knew the acquisition depth of the survey directly and it can be used as the control parameter whether the depth of the survey targets are resolved or not. The length of survey line showed consistently with the length of the survey line that measured manually. A trial survey was conducted over a short distance to estimate the appropriate velocity and the sampling frequency. The trigger interval was decided to be $0.05 \mathrm{~m}$.

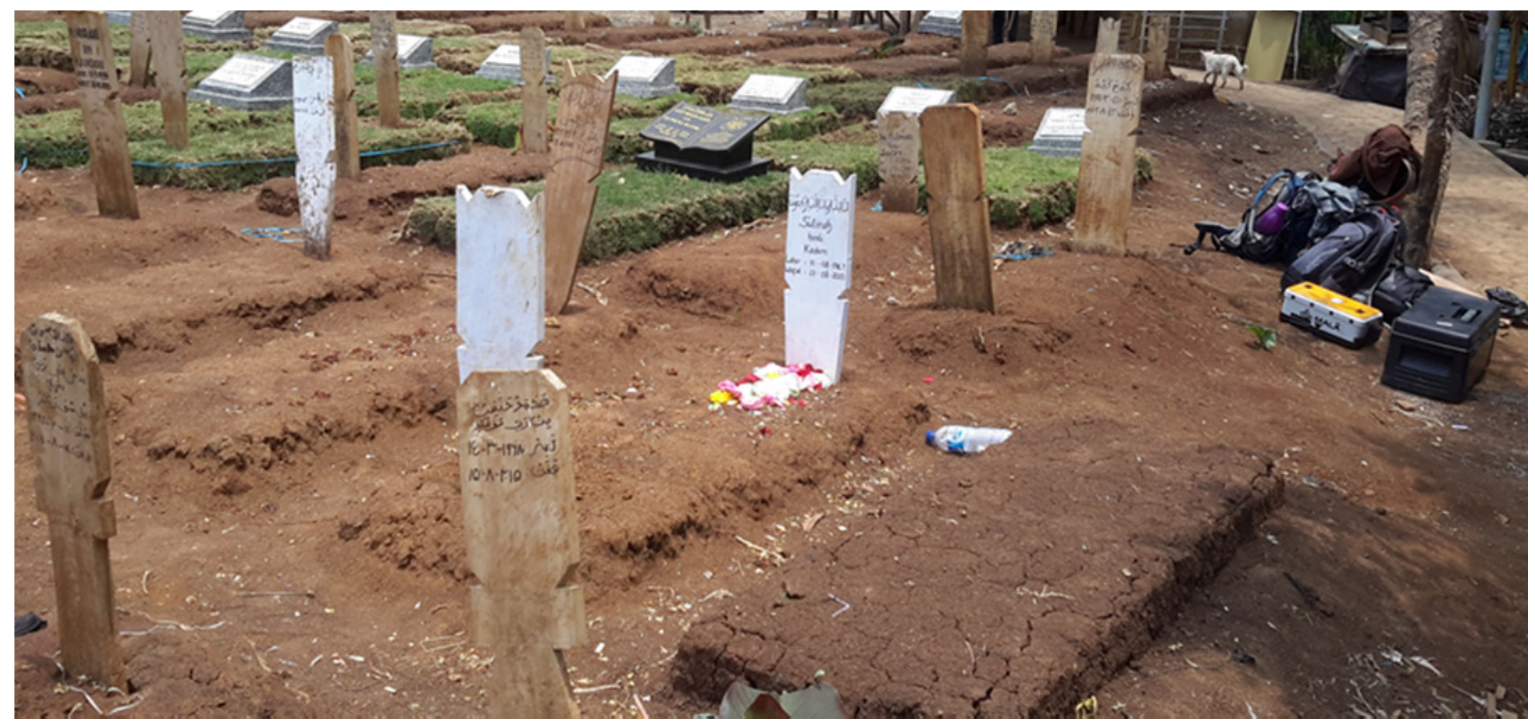

Figure 3. Survey area

Before the actual survey, forward modeling step was conducted by generating the synthetic model of buried human body using MatGPR Release 3 (Tzanis, 2013). Forward modeling is a useful process in geophysics to estimate the geophysical response acquired from the actual survey based on the calculation of a synthetic earth model. The electrical properties used in forward modeling are permittivity and conductivity of soil and buried human bone. The permittivity of soil is defined as $3 \mathrm{~F} / \mathrm{m}$ and the conductivity of soil is defined as $0.05 \mathrm{mho}$. The permittivity of human bone is defined as $23 \mathrm{~F} / \mathrm{m}$ with conductivity defined as 0.7 mho (Foster, 2000). 
Background conductivity is added and defined as 0.05 mho. The frequency of GPR wave that used in forward modeling process is $800 \mathrm{MHz}$ agree with the actual GPR wave that used in the survey.

The line was chosen with maximum offset $12 \mathrm{~m}$. Figure 4 displays the determined line that crossed eleven graves. The head parts of the corpses are on the north and the legs parts of the corpse are on the south part of the grave. The acquisition was measured from west to east. The topography along the survey lines was relatively flat with increasing elevation $10 \mathrm{~cm}$ right above each grave. A board was used to help the instrument moving from one grave to the next grave due to the elevation variation (Figure. 5). The atmospheric condition during the survey was clear with no cloud, rain, or lightning so it could be predicted that there was only a minimal amount of EM wave noise during the survey.
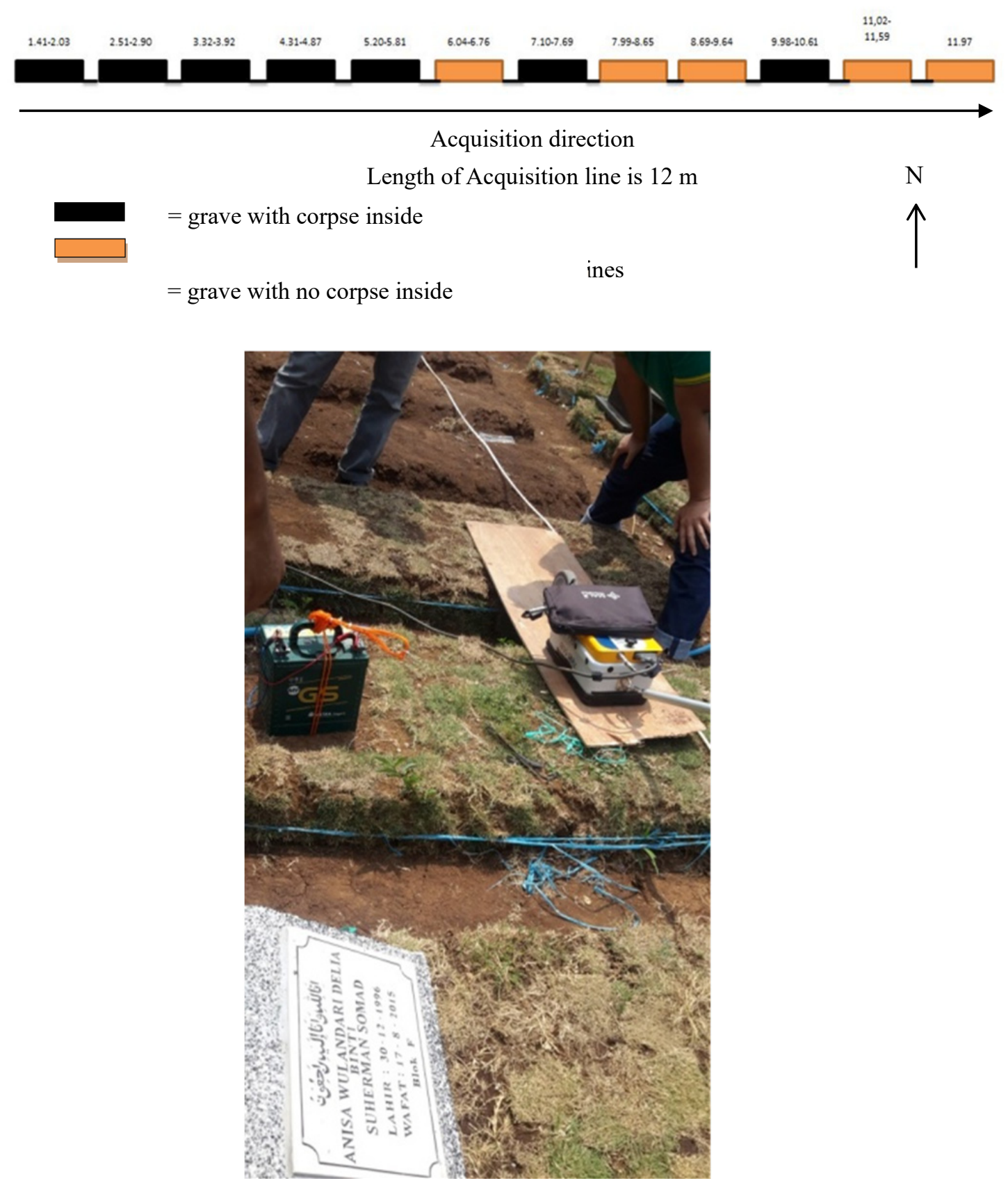

Figure 5. Board used to move the equipment from one grave to another grave

After the real time data processing in survey field using RamacGroundVision software, survey data was processed using ReflexW software. The applied processing steps increase the interpretability of the GPR profiles 
by removing the random noise and enhancing the amplitude response of interest. Moreover, most of the high amplitude air wave and ground wave arrivals that usually disfigure the top of radargrams are effectively removed. The defined processing sequence in ReflexW is shown in Table 1.

Table 1. Processing steps of the GPR Data

\begin{tabular}{lc}
\hline No. & Processing Steps \\
\hline 1. & Static correction \\
2. & Subtract mean (dewow) \\
3. & Band pass filter \\
4. & Background removal \\
5. & Stacking \\
\hline
\end{tabular}

Static correction process is applied to bring the signal into the correct datum. In this research the datum reference that used is mean sea level. Subtract mean (dewow) is applied in all traces to increase the data resolution by choosing only the spike wavelet. The $2.5 \mathrm{~ns}$ time window is used because it results the best spiking wavelet form. The chosen time window value is affected by lithological factors such us soil moisture and type of rock, and it also affected by acquisition parameter such us GPR wave frequency, and the trigger interval. The best time window value will be different for any different survey condition. After subtract mean process, band pass filter is applied to separate the primary signal from noise. Band pass filter that used at this processing stage is $150 \mathrm{MHz}-260 \mathrm{MHz}$ because this value resulting the better appearance of radargram profile. After the band pass filter step, the background noise was not removed completely from the radargram. To remove the left background noise, the background removal process was applied. The last step of processing is stacking that aimed to increase the signal to noise ratio resulting the best appearance of radargram profile.

\section{Discussion and Results}

At the forward modeling stage, two synthetic models were used. The first model is the homogeneous subsurface condition and the second model is non homogeneous subsurface with three corpses appearance in subsurface (Figure 6a). The homogeneous subsurface model is purposed to distinguish the GPR response between the corpse appearance and homogeneous background soil.The GPR frequency used for the forward modeling was $800 \mathrm{MHz}$. The velocity of the radar wave in soil was derived from the electrical properties of the dry soil by MatGPR release 3.0 defined as $0.17022 \mathrm{~m} / \mathrm{ns}$. Meanwhile, the velocity of the radar wave in human bone was derived from the electrical properties of the human bone defined as $0.061642 \mathrm{~m} / \mathrm{ns}$. The GPR response in homogeneous subsurface model shows no anomalies in radargram (Figure 6b) agree with the homogeneous subsurface condition in the first model.

In the second synthetic model, the locations of corpses are at $1.2 \mathrm{~m}$ depth (Figure $6 \mathrm{c}$ ). The GPR response can detect the existence of the corpses very clearly. The subsurface model more that $2.5 \mathrm{~m}$ depth is not resolved in radargram. The amplitude contrasts are shown at travel time $3 \mathrm{~ns}$ (Figure 6d). Because the target depth on actual survey is also on $1.2 \mathrm{~m}$ depth, we can expect that by using the $800 \mathrm{MHz}$ GPR equipment will result the strong anomaly. The contrast electrical properties that used at forward modelling are permtivity, conductivity, and velocity. Meanwhile, the permeability of subsurface component. in two synthetic models are similar. 
a.
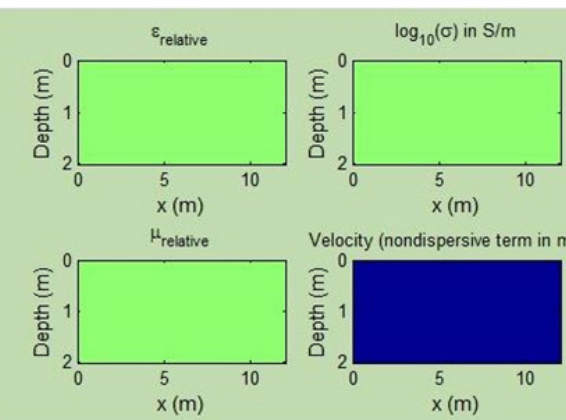

Velocity (nondispersive term in $\mathrm{m} / \mathrm{ns}$ )
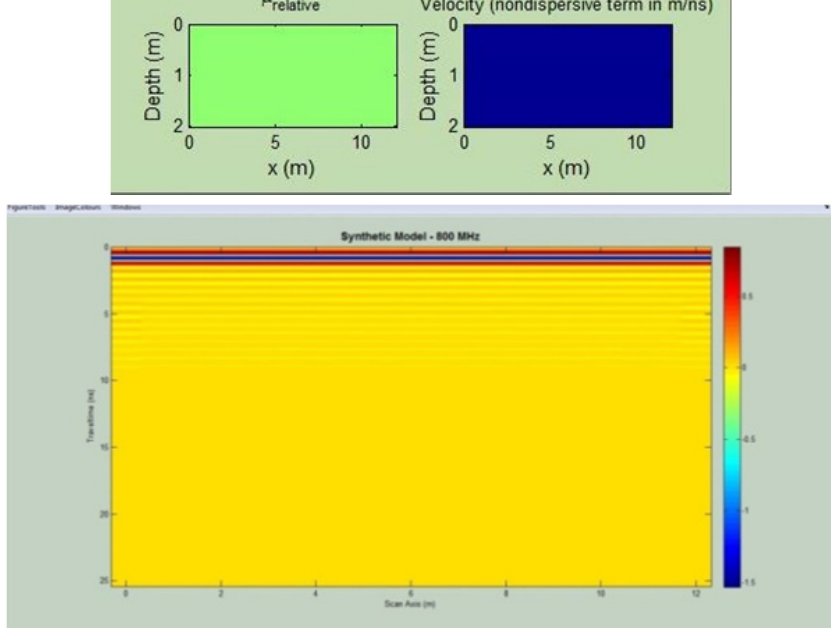

c.
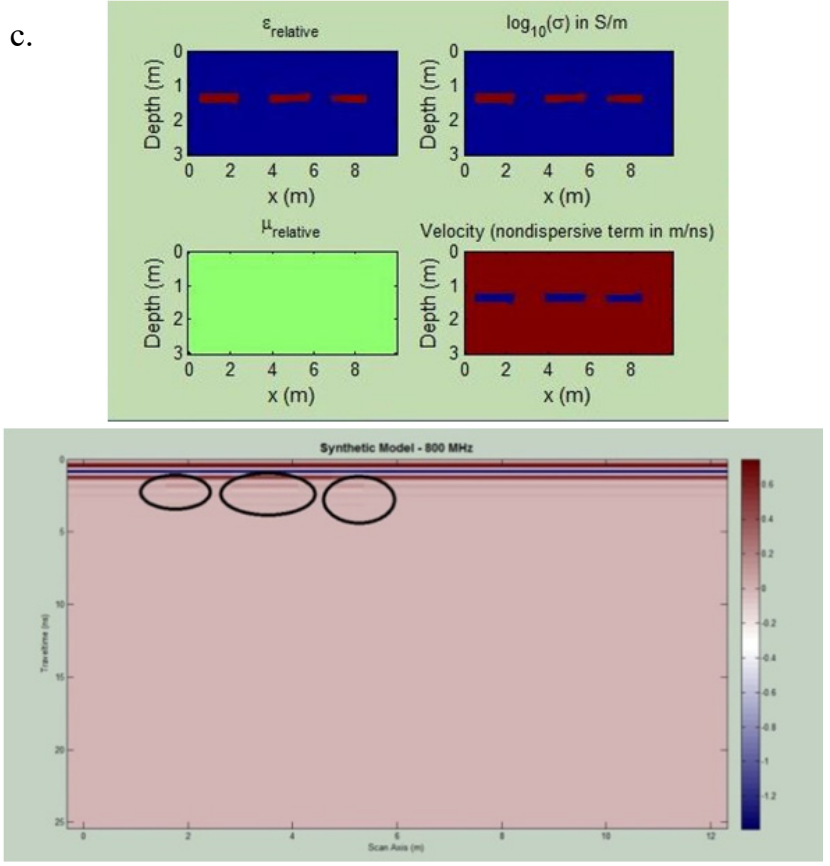

Figure 6. a. First input in forward modeling (homogeneous subsurface). b. Radargram output of first model showing no anomalies. c. Second input in forward modeling (three corpses at $1.2 \mathrm{~m}$ depth) d. Radargram output of second model (black circles show the anomaly by corpses existence)

Penetration depth of $800 \mathrm{MHz}$ GPR wave was well resolved until 2.5 depths as shown in forward modeling shooting simulation (Figure 7). The specification of shooting simulation are the horizontal spacing defined as $0.014 \mathrm{~m}$, the vertical spacing defined as $0.007 \mathrm{~m}$, source-start location defined as $0 \mathrm{~m}$, source-end location defined as $12 \mathrm{~m}$, and the number of source were 256 . 


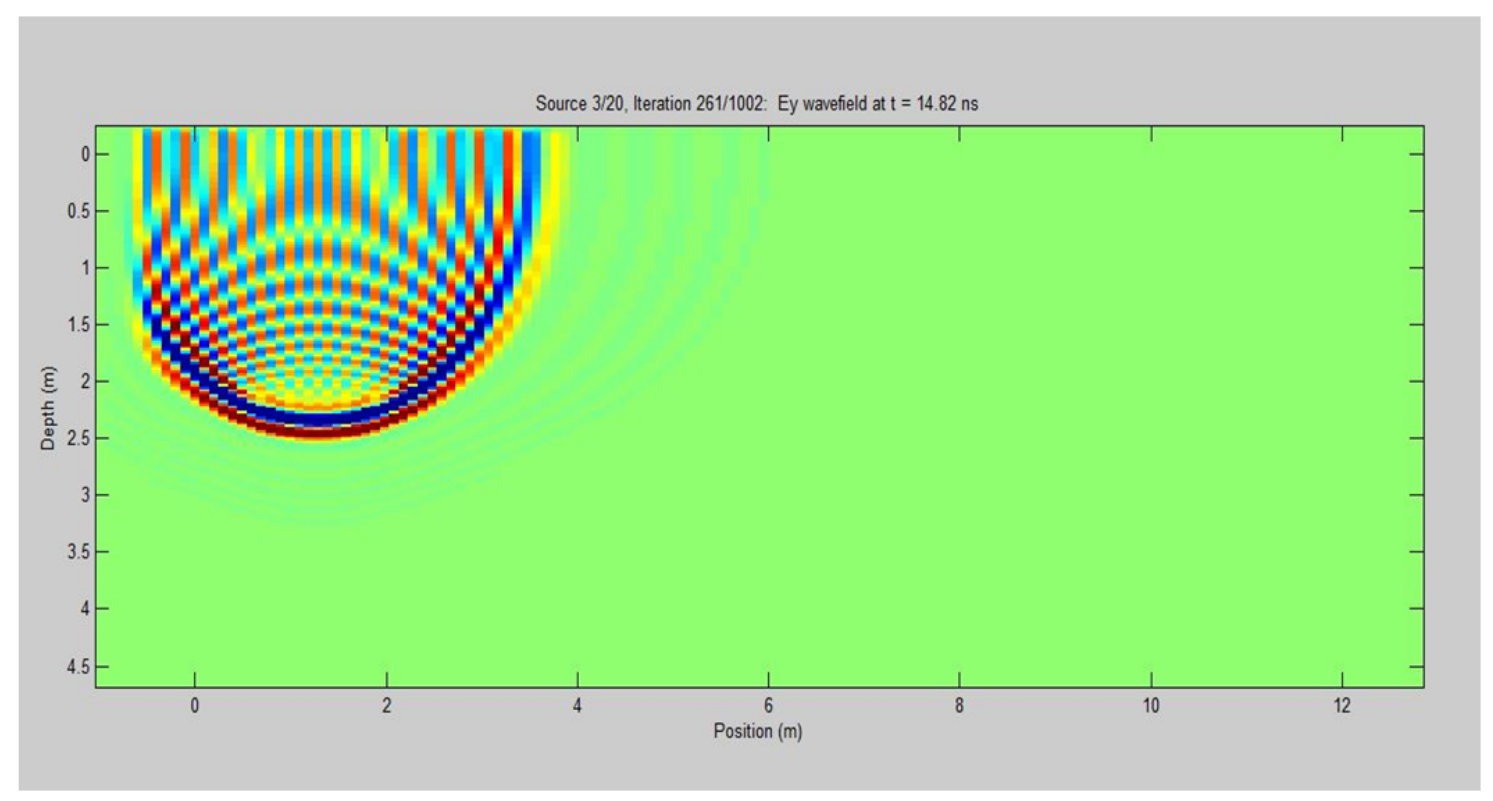

Figure 7. Shooting simulation of $800 \mathrm{MHz}$ GPR wave

a.

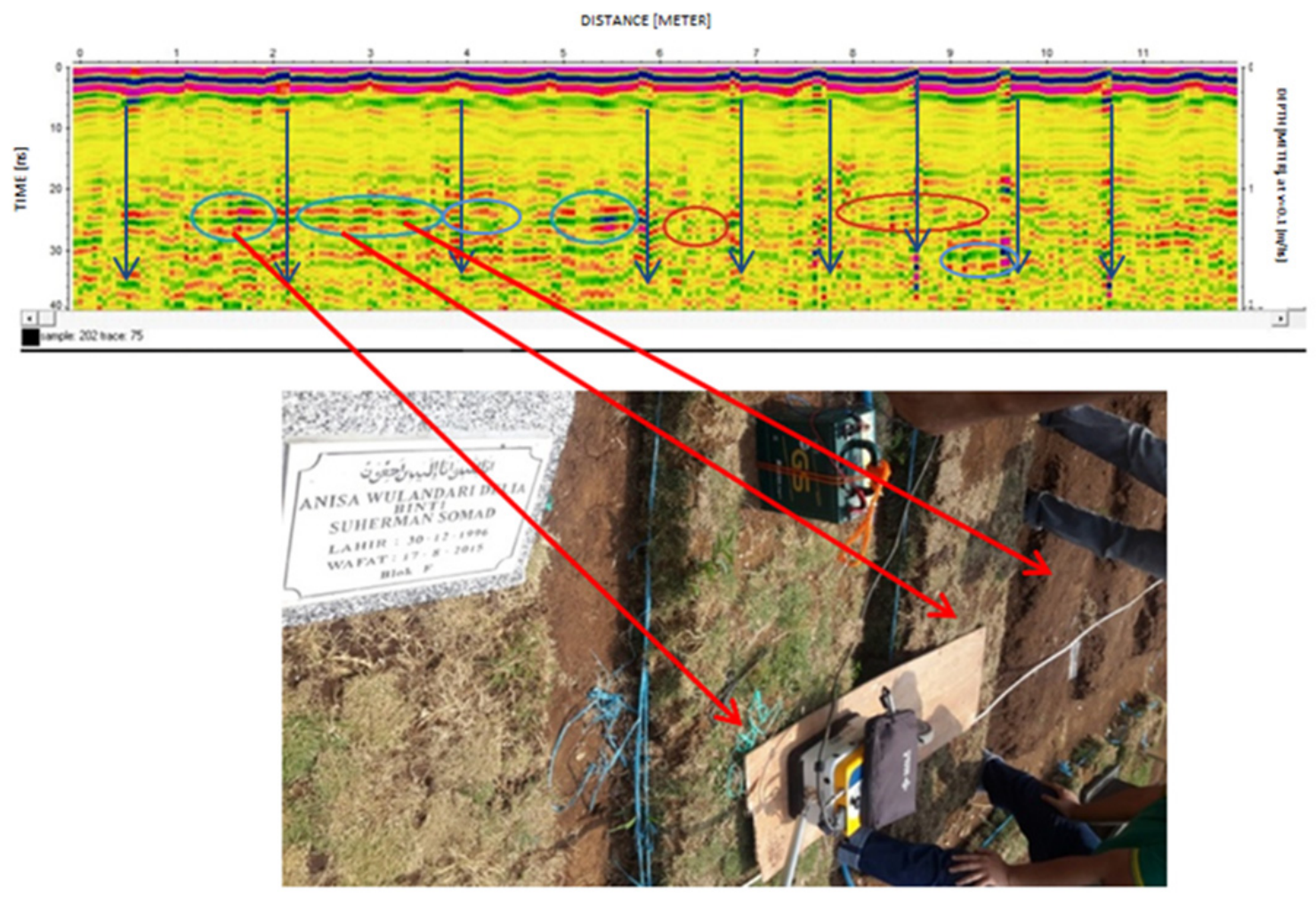


b.

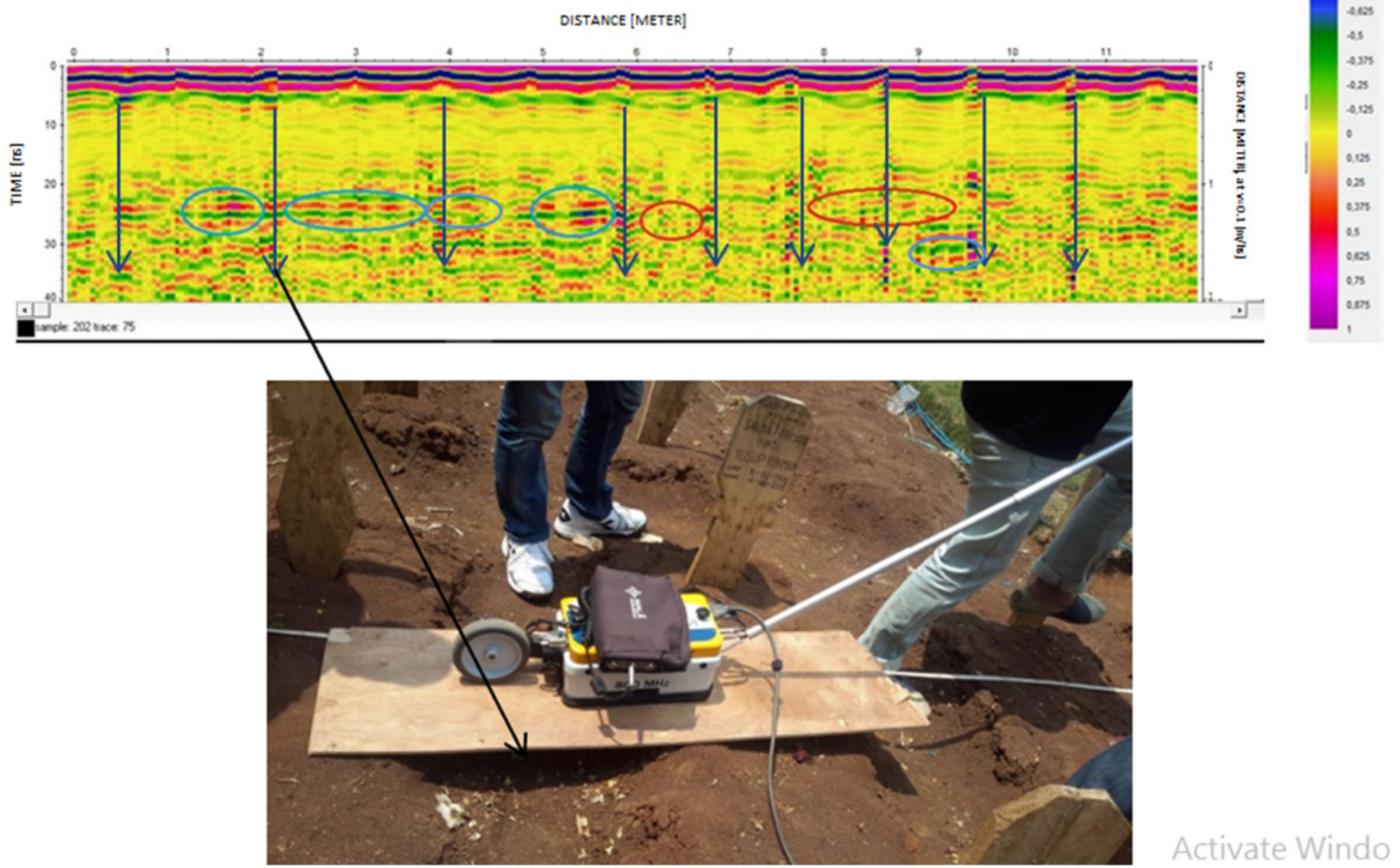

Figure 8.a. Red arrow shows corpse appearence in radargram. b. Black arrow shows the effect of board

Radargram profile showed that components from subsurface materials are visible. These components are unconsolidated rock, undisturbed sand, and amplitude contrasts. The unconsolidated rock is showed by a zero amplitude wave caused by background soil that not being compacted yet in the upper part of radargram profiles. The soil is not well consolidated due to the filling of the graves are less than 2 months prior to the survey. The undisturbed sand is showed by a layering pattern in the lower part of radargram profile because its well consolidates compared to the upper soil.

The amplitude contrasts at around $1.2 \mathrm{~m}$ depth is interpreted as the location where the corpses are buried (marked by the blue circle in Figure 8a) and it was consistent with the depth of actual buried bodies known at Cikutra graveyard that determined as $1.2 \mathrm{~m}$. The empty grave didn't show the contrast amplitude anomaly (marked by red circle in Figure 8a). The black arrow (Figure 8b) show the discontinuity caused by the air effect under the board that used to help the instrument moving from one grave to another grave during acquisition that were agree with its location at field. The discontinuities that lie between graves location are shown in Table 2 . The amplitude contrasts are produced from the contact of EM waves, human blood, and the human bone. The strongest amplitude contrast was interpreted as the electrical properties contrast between human blood, human bone, and background soil. According to Foster (2000) the permittivity of human bone is defined as $23 \mathrm{~F} / \mathrm{m}$ with conductivity defined as $0.7 \mathrm{mho}$, the permittivity of human blood is defined as $58-62 \mathrm{~F} / \mathrm{m}$ with conductivity defined as 1.4 mho. In this survey the strongest amplitude is shown by two weeks coprse compared to other graves that were filled by the older corpses. The most recent corpse is estimated to have more blood than the older copses. For the most recent grave, because the background soil has high contrast conductivity relative to human blood, the amplitude contrasts shown in radargram profile was better displayed. But the oldest corpse in this survey still gave amplitude contrast anomaly compared to the empty grave. This happens due to the contrast electrical properties between the human bone and soil is lower than human blood and soil. So it can be expected to detect the victim in disaster area can be conducted until 2 months after the disaster occurs. To prove the method is also work in detecting the older corpse, the further research must be conducted. This line of survey was only cross the abdomen part of the corpse. To elaborate this research will work if the survey line is crossing the other part of human body, the further research must be conducted.

The anomaly parameter of this survey is different with Damiata et al. (2013) that used the hyperbolic reflection 
as anomaly parameter to show the forensic evidence; meanwhile the anomaly parameter used at this survey is the amplitude contrast. But this research is still giving the good results confirmed by field information.

Table 2. The field information and interpretation

\begin{tabular}{|c|c|c|c|c|}
\hline $\begin{array}{c}\text { Grave number } \\
\text { (from west to east) }\end{array}$ & $\begin{array}{l}\text { Position from } \\
\text { western point }\end{array}$ & $\begin{array}{l}\text { With or without } \\
\text { corpse inside }\end{array}$ & Anomaly showed & Interpretation \\
\hline 1 & $1.41-2.03$ & $\mathrm{~V}$ & Strong anomaly & Recent corpse (contain blood) \\
\hline Discontinuity & $2.03-2.51$ & & & \\
\hline 2 & $2.51-2.90$ & $\mathrm{~V}$ & Strong anomaly & Recent corpse (contain blood) \\
\hline Discontinuity & $2.90-3.32$ & & & \\
\hline 3 & $3.32-3.92$ & $\mathrm{~V}$ & Strong anomaly & Recent corpse (contain blood) \\
\hline Discontinuity & $3.92-4.31$ & & & \\
\hline 4 & $4.31-4.87$ & $\mathrm{~V}$ & Strong anomaly & Recent corpse (contain blood) \\
\hline Discontinuity & $4.87-5.20$ & & & \\
\hline 5 & $5.20-5.81$ & $\mathrm{~V}$ & Strong anomaly & Recent corpse (contain blood) \\
\hline Discontinuity & $5.81-6.04$ & & & \\
\hline 6 & $6.04-6.76$ & $\mathrm{X}$ & No anomaly & Empty grave \\
\hline Discontinuity & $6.67-7.1$ & & & \\
\hline 7 & $7.10-7.69$ & $\mathrm{X}$ & No anomaly & Empty grave \\
\hline Discontinuity & 7.69-7.99 & & & \\
\hline 8 & $7.99-8.65$ & $\mathrm{~V}$ & No anomaly & Oldest corpse \\
\hline Discontinuity & $8.65-8.69$ & & & \\
\hline 9 & $8.69-9.64$ & $X$ & No anomaly & Empty grave \\
\hline Discontinuity & $9.64-9.98$ & & & \\
\hline 10 & $9.98-10.61$ & $\mathrm{~V}$ & Strong anomaly & Recent corpse (contain blood) \\
\hline Discontinuity & $10.61-11.02$ & & & \\
\hline 11 & $11.02-11.59$ & $\mathrm{X}$ & No anomaly & Empty grave \\
\hline Discontinuity & $11.59-11.97$ & & & \\
\hline 12 & 11.97 & $\mathrm{X}$ & No anomaly & Empty grave \\
\hline
\end{tabular}

\section{Conclusion}

The use of GPR $800 \mathrm{MHz}$ equipment can map the subsurface well until $2.5 \mathrm{~m}$ depth. The amplitude contrast anomaly at the depth around $1.2 \mathrm{~m}$ is indicated as the location of the buried bodies, and consistent with the depth of actual buried bodies known at Cikutra graveyard that determined at $1.2 \mathrm{~m}$. The air effect caused by the hole in subsurface can result the discontinuities at radargram profile. The contrast amplitude was strongest at the most recent grave compared to the older grave because of the human blood in the younger corpses give bigger contrast with soil compared with the contrast of the human bones with soil. This supports the initial hypothesis that the GPR method can be used to detect a human body buried underground or under disaster avalanches. However, further research is needed in an actual landslide or earthquake area to investigate the GPR reflection pattern at the landslide cite. Moreover, additional research to remove the effect of subsurface hole and the survey with 
different GPR wave frequency are important.

\section{References}

Conyers, L. B. (2004). Ground-penetrating radar for archaeology.AltaMira Press.

Conyers, L. B., \& Goodman, D. (1997). Ground-penetrating radar (pp. 149-194). An Introduction for Archaeologist: AltaMira Press.

Damiata, B. N., Steinberg, J. M., Bolender, D. J., \&Zoëga, G. (2013). Imaging skeletal remains with ground-penetrating radar: comparative results over two graves from Viking Age and Medieval churchyards on the Stóra-Seyla farm, northern Iceland. Journal of Archaeological Science, 40(1), 268-278.

Hammon III, W. S., McMechan, G. A., \&Zeng, X. (2000). Forensic GPR: finite-difference simulations of responses from buried human remains. Journal of Applied Geophysics, 45(2000), 171-186.

Mellett, J. S. (1992, June). Location of human remains with ground-penetrating radar. In: Hanninen, P., Autio, S. (Eds), Geological Survey of Finland, Special Paper 16, Fourth International Conference on Ground Penetrating Radar, pp. 359-365.

Neal, A. (2004). Ground-penetrating radar and its use in sedimentology: principles, problems and progress. Earth-science reviews, 66(3), 261-330.

Robinson, M., Bristow C., McKinley, J., \&Ruffell, A. (2004).Ground Penetrating Radar, Geomorphological Techniques, Part 1, Sec. 5.5.

Tzanis, A. (2013). MatGPR (Release 3), Manual and Technical Reference.University of Athens, Department of Geophysics.

\section{Copyrights}

Copyright for this article is retained by the author(s), with first publication rights granted to the journal.

This is an open-access article distributed under the terms and conditions of the Creative Commons Attribution license (http://creativecommons.org/licenses/by/3.0/). 